\title{
Avaliação do perfil mediacional de uma professora da educação infantil
}

\author{
Helena de Ornellas Sivieri Pereira \\ Eulália Henriques Maimone \\ Aline Patrícia Oliveira
}

\begin{abstract}
Resumo
Esta pesquisa objetivou examinar o perfil mediacional de uma professora de Educação Infantil, baseando-se no enfoque da Psicologia HistóricoCultural, buscando ressaltar a importância da formação continuada de professores. Foram realizadas vídeogravações da interação da professora com as crianças na faixa etária de $5 / 6$ anos de uma instituição de Educação Infantil de Minas Gerais, Brasil. Estas vídeogravações foram transcritas e validadas pela professora e, posteriormente, analisadas com base na Escala de Empenhamento do Adulto. Essa escala analisa as características pessoais e profissionais que definem a capacidade de interação da educadora no processo de ensino e aprendizagem: sensibilidade, autonomia e estimulação. A professora apresentou tais características, contudo, sensibilidade e autonomia aparecem em níveis mais baixos, indicando que ela tem um perfil mais voltado para estimulação da aprendizagem. Esses dados oferecem base para intervenções futuras em formação de professores da Educação Infantil.
\end{abstract}

Palavras-chave: Educação Infantil, mediação da aprendizagem, formação de professores.

\section{Evaluation of the profile of a mediational professor of early childhood education}

\begin{abstract}
In this study we examine the mediational profile of an early childhood teacher, based on the Historical-Cultural Psychology; We emphasize the importance of continuous training of teachers. We produced Video recordings of the interaction of teacher with children aged $5 / 6$ years of an institution of Early Childhood Education of Minas Gerais, Brazil. These video recordings were transcribed and approved by the teacher and then analyzed based on the Adult Engagement Scale. This scale examines the personal and professional characteristics that define the interaction capacity of the educator in the teaching and learning:. The teacher showed these characteristics, however, sensitivity and autonomy appear at lower levels, indicating that she has a profile more focused on stimulation of learning. These data provide a basis for future interventions in teacher education from kindergarten.
\end{abstract}

Keywords: Early childhood education, learning mediation, teacher education.

\section{Evaluación del perfil mediacional de una profesora de educación infantil}

\section{Resumen}

Esta investigación tuvo el objetivo de examinar el perfil mediacional de una profesora de Educación Infantil, con base en el enfoque da Psicología Histórico-Cultural, buscando resaltar la importancia de la formación continuada de profesores. Se realizaron grabaciones en video de la interacción de la profesora con niños con edades entre 5/6 años de una institución de Educación Infantil de Minas Gerais, Brasil. Se transcribieron las grabaciones, fueron validadas por la profesora y, posteriormente, se analizaron con base en la Escala de Empeño del Adulto. Esta escala analiza las características personales y profesionales que definen la capacidad de interacción de la educadora en el proceso de enseñanza y aprendizaje: sensibilidad, autonomía y estimulación. La profesora presentó tales características, sin embargo, sensibilidad y autonomía aparecen en niveles más bajos, indicando que tiene un perfil más inclinado para estimulación del aprendizaje. Estos datos ofrecen base para intervenciones futuras en formación de profesores de Educación Infantil.

Palabras clave: Educación Infantil, mediación del aprendizaje, formación de profesores. 


\section{Introdução}

Muito se tem falado nos meios educacionais em mediação e no papel mediador do professor, mas pouco se revela acerca de como isso acontece na situação real de sala de aula.

O propósito da presente pesquisa foi o de examinar o estilo mediacional de uma professora de Educação Infantil, no momento mesmo de sua atuação em aula, em uma creche comunitária, que servisse de subsídio para o planejamento e execução de um projeto de formação de professores.

Para isso, fez-se uso de um instrumento de observação da professora em sala de aula que tem sido utilizado por pesquisadores nacionais e internacionais, conforme Maimone e Tomás (2005). Foi desenvolvido por Bertram (1996, conforme citado por Formosinho \& Formosinho, 2001), que chegou a "três âmbitos de acção da educadora" que podem ser observados:

1) sensibilidade do adulto para com a criança (aos seus sentimentos de bem estar emocional e aos seus interesses pessoais) [...], 2) grau de liberdade que o adulto oferece à criança, isto é, a autonomia que Ihe confere [...] e 3) o grau de estimulação que o adulto oferece à criança. (p. 92).

A pesquisa de Maimone e Tomás (2005), utilizando tal instrumento em contexto brasileiro, mostrou que professoras de creche pública tendiam a dar pouca autonomia à criança mais jovem, talvez por considerá-la ainda incapaz de realizar sozinha suas atividades escolares, como explicam as autoras, sugerindo que esse aspecto fosse enfatizado em oportunidades de formação continuada de professores da Educação Infantil.

Estudos anteriores, como os de Pnina Klein (1996), já haviam indicado a possibilidade de registros de interações entre adultos e crianças pequenas fornecerem informações importantes sobre o estilo mediacional de mães e cuidadoras, com o objetivo de orientar um programa de formação para as mesmas. A autora considerou cinco critérios mediacionais: focalização, expansão, afetividade, regulação de comportamento e sentimentos de competência. Esses mesmos critérios serviram de base para uma pesquisa brasileira sobre a parceria entre família e escola (Maimoni \& Bortone, 2003), em um projeto para melhorar o desempenho de alunos do início do Ensino Fundamental, em escola do interior mineiro, em leitura, bem como indicando aos pais formas concretas de colaboração com a escola. Por outro lado, professoras tiveram a oportunidade de vivenciar uma experiência de como obter a participação dos pais no processo de aprendizagem da leitura dos filhos. Utilizando esses mesmos critérios, Silva (2004) elaborou proposta de formação de professores e Tomás (2010) observou mães sociais em abrigos, encontrando que o critério mais utilizado pelas mesmas foi o de regulação de comportamento, indicando, segundo a autora, a necessidade de programa contínuo de formação para essas pessoas.
Independentemente dos critérios escolhidos pelos autores, vale ressaltar as suas contribuições científicas, uma vez que o trabalho de observação exige do pesquisador grande gasto de tempo, além de depender da adesão das instituições educacionais e dos professores participantes. Estes nem sempre se sentem confortáveis ao serem filmados em situação de sala de aula. A videografia é um recurso muito utilizado por pesquisadores em estudos dessa natureza, que requerem auxiliares de pesquisa preparados e cuidadosos no trato com aqueles que se dispõem a passar por essa situação. Assim, conforme considerações de Sadalla e Larocca (2004), no seu texto sobre autoscopia, deve ficar bem claro, para todos os participantes desse tipo de pesquisa, como serão utilizados os registros de observação, ressaltando seu potencial formativo, ao possibilitar ao professor observar-se atuando.

Tomar como ponto de partida a prática social escolar, registrada ou não em vídeo, tem sido também uma forma que pesquisadores encontraram para chegar a uma proposta de formação continuada de professores que pudesse corresponder às reais necessidades de formação docente (Gonçalves \& Maimone, 2008).

Dermeval Saviani, importante pensador da Educação Brasileira, que formulou a teoria da Pedagogia Histórico-Crítica, ressalta, por meio de uma proposta de formação continuada de professores, elaborada por sua equipe, dentro de princípios do materialismo histórico e dialético, a necessidade de não só iniciar pela prática social do professor, mas também voltar a essa prática já modificada pelo processo catártico, como ponto de chegada na formação docente (Mazzeu, 1998). Em vista disso, pode-se falar de uma aproximação entre as ideias desse pensador e as de Vigotski (1987, 1988, 2003), autor que utilizou esses mesmos princípios filosóficos na construção de uma psicologia marxista, nomeada por ele como Psicologia Histórico-Cultural. Essa aproximação é mostrada em Gasparin (2005) e argumentada em Maimone e Gonçalves (2010). Em consequência da adoção desse modelo teórico, o principal conceito vigotskiano foi o de mediação, segundo o qual, de acordo com a filosofia marxista, o homem não se relaciona diretamente com o mundo. Na aprendizagem sobre as práticas da cultura, em que é mergulhada logo ao nascer, a criança necessita da mediação de um membro dessa cultura, de início a mãe e familiares e, mais tarde, já na escola, onde se dá a transmissão do conhecimento sistematizado, o professor e os colegas. Como cada vez mais cedo a criança tem sido deixada aos cuidados de instituições de Educação Infantil, o conhecimento de como se dá o processo mediacional na interação da criança com os adultos, fora da família, se faz bastante necessário. E isso só é possível pela observação da prática do professor de Educação Infantil no ambiente escolar.

A Educação Infantil no Brasil passou por grandes transformações nas últimas três décadas, conforme mostram autores como Campos (1994), Kramer (1999, 2001), Oliveira, Mello, Vitoria e Rossetti-Ferreira (1992) e Ramos (2007), entre outros. Sem pretender fazer um retrospecto histórico da criação e desenvolvimento das creches no país, 
é importante lembrar que, nas décadas dos anos 70 e 80 , o atendimento a crianças de até seis anos nas chamadas pré-escolas ainda se pautava pelo modelo médico e maternal, ou seja, buscando que, na creche, a criança fosse atendida em suas necessidades básicas de higiene, alimentação e brincadeiras.

Com a Lei de Diretrizes e Bases da Educação, promulgada em 1996, este quadro muda, ao incluir a Educação Infantil como a primeira etapa da Educação Escolar Básica, atendendo a criança até os seis anos de idade e tentando evitar a separação entre o trabalho assistencial à infância e o escolar fornecido à infância. Mesmo com essas disposições legais, até 2005, de acordo com Ramos (2007), pesquisadores constatavam que mudanças importantes ainda não haviam ocorrido e apontavam para a necessidade de formação do professor para atuar dentro de novos papéis, com o devido "resguardo das especificidades da Educação Infantil, reveladas no binômio cuidar-educar, que a difere do modelo escolar" (p. 88).

Percebe-se que, dentre outras, estas são algumas questões que poderão levar o professor de Educação Infantil a rever seu trabalho, a reelaborar metodologias e critérios de atuação, o que muitas vezes pode provocar no docente uma grande insegurança, o que só mesmo um programa contínuo de formação docente possibilitará reduzir, auxiliando-o no seu novo cotidiano escolar. Por outro lado, são as dificuldades encontradas pelo professor que parecem ativar a sua zona de desenvolvimento proximal, tal como acontece com a criança, nas suas dificuldades de aprendizagem. A proposta vigotskiana sobre o desenvolvimento e a aprendizagem do homem coloca ênfase nesse momento proximal, em que um aprendiz não consegue realizar uma tarefa do seu dia a dia e necessita do auxílio de outra pessoa, a fim de alcançar o próximo desenvolvimento, com essa nova aprendizagem.

Quanto ao professor, igualmente a presença de um outro mais experiente, que o auxilie em suas dificuldades, pode contribuir para seu processo contínuo de formação. Maimone, Oliveira, Vieira e De Pieri (2007) demonstraram como isso pode se dar na formação de professores da Educação Infantil, em uma situação real de turmas de crianças de três, quatro e cinco anos, quando a necessidade da instituição era a de melhorar o relacionamento família-escola e valorizar o brincar dentro da instituição. As autoras relataram que, além do recurso à videogravação da prática da professora, que era assistida primeiro pela própria professora, para depois ser apreciada pelas colegas, no grupo de formação, juntamente com as pesquisadoras, houve a solicitação de que todos os presentes auxiliassem a colega ou valorizassem seus estilos de mediação, que eram mostrados no vídeo. Na sessão seguinte, era a vez de outra professora, até que todas as voluntárias na pesquisa pudessem passar por essa experiência de aprendizagem, a partir de sua própria prática. Também nos momentos de formação, os textos dos teóricos da Psicologia Histórico Cultural sobre mediação, zona de desenvolvimento proximal e a atividade principal da criança, que é o brincar, iam sendo apropriados pelos participantes.
Portanto, observar o estilo mediacional de professores tem sido uma metodologia utilizada por pesquisadores da educação e áreas afins, mas ainda há muito o que fazer para que seja possível concluir sobre o estilo mediacional docente, uma vez que, em diferentes contextos educacionais, estilos diversos podem se configurar.

O presente estudo teve a preocupação de buscar um tipo de instituição que tem preenchido, bem ou mal, a necessidade da população por mais vagas para as crianças na Educação Infantil, que é a creche comunitária, o que o difere do trabalho brasileiro de Maimoni e Tomás (2005), referido anteriormente, que aconteceu em instituição municipal. Foi, portanto, uma oportunidade de conhecer a atuação de uma professora em um ambiente que aparentava ser diferente daquele em que se dá a Educação Infantil pública.

\section{Objetivo}

Conhecer o perfil mediacional de uma professora da Educação Infantil, com a utilização da Escala de Empenhamento do Adulto, tal como descrita em Maimoni e Tomás (2005).

\section{Metodologia}

A metodologia foi qualitativa, chamada por Newman e Holzman (2002, p. 45), de metodologia instrumento-e-resultado, utilizando-se o modelo de avaliação em processo, em que os sujeitos que participam do estudo são avaliados durante o processo de desenvolvimento de uma atividade, neste caso, uma atividade realizada no ambiente escolar. Atividade é aqui entendida tal como Newman e Holzman (2002) a definem, com base em Vigotski, como "atividade humana (histórica) ordinária, cotidiana, de cada hora: é uma ação particular, a, mudando a totalidade das circunstâncias ('cenários' históricos) da existência humana B, C, D... e combinações de circunstâncias B, C e D etc." (p. 60). A videografia foi a forma de registro dessa atividade da professora, para posterior análise de seu empenho.

Bertram e Laevers (1996, citados por Maimone \& Tomás, 2005) definem empenho como a capacidade de o professor ser sensível a momentos em que deve exercer a mediação em situações de aprendizagem de seus educandos, ser estimulador, ao propor experiências de aprendizagem e saber promover a autonomia da criança.

\section{Sujeitos}

A pesquisa foi realizada em uma creche comunitária de uma cidade do interior de Minas Gerais, a qual atende crianças de três a seis anos. Na época da pesquisa, contava com quatro professoras e sete funcionários para 46 crianças. Tal instituição funciona em horário integral, de segunda a sexta-feira, e é mantida por uma associação espírita, con- 
tando com o espaço de três salas de aulas, parquinho, sala para exames médicos, refeitório e sala de administração.

Participaram das filmagens uma professora do período matutino e seus dezesseis alunos, que possuíam idades entre 05 e 06 anos, tendo esse registro ocorrido, portanto, pela manhã, após o horário do lanche. A professora é formada em Pedagogia e tem três anos de experiência profissional nessa instituição.

\section{Procedimentos de coleta de dados}

Foram feitas quatro filmagens, sendo três em sala de aula e uma no parquinho da creche, cada uma com duração de aproximadamente uma hora. Todas as crianças presentes nos dias marcados para observação e a professora eram filmadas em sua interação, não havendo nenhuma interferência das pesquisadoras.

\section{Procedimentos de análise dos dados}

Transcritos os vídeos e validados pela professora, o estilo mediacional foi analisado nas transcrições pela Escala de Empenhamento do Adulto, em tradução feita em Portugal para o título em inglês Adult Engagement Scale. Foi desenvolvida por Bertram (1996, citado por Formosinho \& Formosinho, 2001, p. 92), que chegou a "três âmbitos de acção da educadora", que podem ser observados e classificados em cinco níveis: 1) sensibilidade do adulto para com a criança, em relação aos seus sentimentos de bem estar emocional e aos seus interesses pessoais; 2) grau de liberdade que o adulto oferece à criança, isto é, a autonomia que lhe confere e 3) o grau de estimulação que o adulto oferece à criança" (p. 92).

É uma escala descritiva, para auxiliar na análise das filmagens, e já foi utilizada no Brasil com o título de Escala de Empenho do Adulto, por Maimoni e Tomás (2005).
Para se obter maior fidedignidade dos dados de observação, dois juízes independentes analisaram o material filmado para classificar o empenho da professora em relação aos três âmbitos de ação ou critérios de avaliação: sensibilidade, estimulação e autonomia. Para essa avaliação, os juízes assistiram antes a um vídeo, com situações de sala de aula para serem ser classificadas, organizado por Pascal e Bertram (1996) para treino de avaliadores.

Após esse treino, cada um dos juízes atribuiu a cada um dos três critérios uma pontuação de 1 a 5 , sendo o nível 5 o mais alto índice a ser alcançado, conforme descrevem Formosinho e Formosinho (2001):

Nível cinco: representa um estilo de empenho total.

Nível quatro: representa um estilo predominante de empenho, mas com algumas atitudes de falta de empenho.

Nível três: representa um estilo onde não predominam nem as atitudes de empenho, nem as de falta de empenho.

Nível dois: representa um estilo principalmente de falta de empenho, porém é possível observar algumas atitudes de empenho. empenho.

Nível um: representa um estilo de ausência total de

\section{Resultados}

Os resultados estão apresentados na Tabela 1, que mostra a frequência e a porcentagem de cada nível de empenho da professora em relação aos três critérios de análise.

Puderam ser observados, por meio das filmagens realizadas na creche, trinta momentos de empenho do adulto, sendo dezessete classificados dentro do critério estimulação, com maior frequência no nível 3. A segunda ocorrência, em termos de frequência, foi sensibilidade, com 8 momentos, mas situados em maior frequência no nível 1, com seis momentos. O nível 1 representa, segundo a escala

Tabela 1. Frequência e porcentagem das categorias de estimulação, autonomia e sensibilidade da professora observada, em cada nível de empenho.

\begin{tabular}{lllllllll}
\hline Níveis lempenho & \multicolumn{2}{c}{ Estimulação } & \multicolumn{2}{c}{ Autonomia } & \multicolumn{2}{c}{ Sensibilidade } & \multicolumn{2}{c}{ Total } \\
\hline \multirow{2}{*}{ Nível 1 } & $\mathrm{F}$ & $\%$ & $\mathrm{~F}$ & $\%$ & $\mathrm{~F}$ & $\%$ & $\mathrm{~F}$ & $\mathbf{\%}$ \\
Nível 2 & 2 & 6,7 & 2 & 6,7 & 6 & 20 & $\mathbf{1 0}$ & $\mathbf{3 3 , 4}$ \\
Nível 3 & 2 & 6,7 & 0 & 0 & 1 & 3,3 & $\mathbf{3}$ & $\mathbf{1 0}$ \\
Nível 4 & 6 & 20 & 3 & 10 & 1 & 3,3 & $\mathbf{1 0}$ & $\mathbf{3 3 , 4}$ \\
Nível 5 & 4 & 13,3 & 0 & 0 & 0 & 0 & $\mathbf{4}$ & $\mathbf{1 3 , 3}$ \\
Total & 3 & 10 & 0 & 0 & 0 & 0 & $\mathbf{3}$ & $\mathbf{1 0}$ \\
\hline
\end{tabular}


utilizada, uma ausência total de empenho. Por fim, aparece autonomia, com apenas 5 ocorrências, tendo a sua maior frequência no nível 3 , relacionado ao não predomínio de empenho e nem à falta de empenho, mas aparecendo, em seguida, o nível 1 da escala, com quase metade do valor da frequência total.

Esses resultados podem representar que, por se tratar de um ambiente escolar, a professora procura intervir no processo de aprendizagem das crianças, com um estilo mediacional voltado para a estimulação. Ressalta-se aqui que a estimulação presente não se dá no sentido de ativar o imaginário infantil nas atividades da Educação Infantil, mas sim na tentativa de promover as tarefas de preparação para a leitura e escrita, priorizando o modelo escolar, que não atende à necessidade de brincar das crianças nessa faixa etária. Mas como a estimulação se deu mais no nível 3, que se refere ao não predomínio nem do empenho e nem da falta de empenho, percebe-se que ainda existe uma necessidade de maior empenho da professora, mesmo visando à preparação escolar para a alfabetização. De qualquer maneira, esse foi o índice em que se pode verificar a maior porcentagem dos comportamentos de empenho da professora, na sua interação com as crianças.

Os baixos resultados relacionados ao critério sensibilidade podem ser interpretados como um estilo mediacional pouco sensível às necessidades das crianças, dado esse que encontra apoio, por exemplo, na fala da professora, presente na filmagem, quando se aproxima de algumas crianças, as quais não permitiu que brincassem e que deviam ficar olhando as outras crianças brincarem no parque, como punição:

...não quero que cheguem perto uns dos outros. É ruim ficar olhando os coleguinhas brincarem, não é?

Esse exemplo evidencia a forma como o parquinho é utilizado por essa professora. As crianças mais ativas do ponto de vista psicomotor são punidas pela privação da atividade lúdica. Esse recurso é utilizado para controle do seu corpo, em lugar de ser um momento para que essa necessidade de atividade motora possa encontrar a satisfação. Será que os resultados obtidos estão beneficiando o desenvolvimento dessas crianças? Se o brincar é pouco estimulado na instituição, fato observado nessa etapa da pesquisa e na anterior, no período da manhã, privar as crianças desse momento no parquinho é impedi-las de exercer sua atividade principal nessa faixa etária (Leontiev, 1988). Seria como privar o adulto de trabalhar. Reflexões como esta poderiam ser propiciadas em momentos de formação continuada de professores na instituição, em que os vídeos dessas situações pudessem ser assistidos pelo pessoal da creche e serem discutidos por todos, a fim de encontrar novas medidas disciplinares que sejam eficazes e não limitem o desenvolvimento infantil.

Por outro lado, os resultados apresentados por essa professora, relacionados ao critério autonomia, mostram um estilo mediacional voltado para o modelo do cuidado ma- terno, indicando sua dificuldade no desempenhar de suas funções docentes, oscilando entre o cuidar e o educar. A falta de autonomia concedida à criança pode ser exemplificada pela fala da professora quando propõe uma atividade de montagem de uma flor em EVA, na qual ela determina a maior parte das cores que os alunos terão que usar:

... bom, o que vocês podem fazer: se colocarem o miolo de amarelo, irão colocar todo miolo de amarelo.

Outro dado que pode ilustrar o estilo mediacional dessa professora presente na filmagem refere-se a um dia em que a atividade programada para as crianças foi ver um filme. Em nenhum momento, a professora realizou alguma intervenção a partir deste filme no próprio dia em que foi assistido, porque estava terminando os preparativos para o dia das mães e criando murais para a escola. Pergunta-se: sua preocupação primeira naquele momento estava em fazer bem feitas as apresentações às mães e o mural, ou nas necessidades, curiosidades e questionamentos que poderiam surgir nas crianças? Sua atenção estava toda voltada para a sua atividade e não para a atividade das crianças, mostrando uma dicotomia na atividade de ensino, sem nenhuma interação com as crianças, ocupando-as com o filme para que não atrapalhassem sua própria atividade, desvinculada da atividade propiciada às crianças. Isso pode explicar porque, no critério sensibilidade, a maior frequência tenha sido no nível 1 e de autonomia no nível 3, parecendo não serem sua primeira preocupação essas questões. Seu estilo mediacional, portanto, foi caracterizado pela estimulação da criança em situação de aprendizagem escolar e lúdica dirigidas. Ou seja, não apareceram nas filmagens momentos de atividade livre, em que estivesse presente a brincadeira de faz de conta, momento privilegiado de expressão do imaginário infantil, como bem argumentam Vectore e Kishimoto (2001), por permitir conhecer melhor essa atividade infantil. Para Leontiev (1988, p. 64), "Os processos infantis da imaginação ativa, por exemplo, são inicialmente moldados no brinquedo e os processos de pensamento abstrato, nos estudos". Portanto, privar a criança de brincar e focalizar mais na aprendizagem da leitura e escrita pode comprometer o seu desenvolvimento nessa faixa etária.

\section{Discussão}

Com a implantação da escola de nove anos pelo governo de Minas Gerais, a Educação Infantil perdeu um ano de atividades lúdicas que atenderiam as necessidades da criança pequena de brincar, uma vez que, no seu último ano, caso desta pesquisa, já devem ser focalizadas atividades preparatórias à alfabetização. Isso pode explicar, em parte, o estilo mediacional dessa professora, caracterizado pela estimulação de tarefas escolares com o objetivo de uma iniciação à leitura e escrita. Assim, pode-se observar que políticas públicas podem refletir-se no empenho da professora 
em sala de aula, principalmente se compararmos os seus resultados com os da observação de professoras de Educação Infantil registrados antes da implantação da escola de nove anos na mesma cidade do interior de Minas Gerais. A referida pesquisa mostrou que o estilo mediacional de seis professoras de uma creche municipal caracterizou-se mais pela sensibilidade do adulto para com a criança pequena em relação aos seus sentimentos de bem estar emocional e aos seus interesses pessoais, do que pelos critérios de estimulação e autonomia (Maimoni \& Tomás, 2005). O mesmo resultado havia sido observado por Formosinho e Formosinho (2001) com 102 professores da Educação Infantil em Portugal com a utilização dessa escala de observação. Um resultado baixo como o encontrado nesta pesquisa pode comprometer a qualidade do ensino ministrado para essa turma de crianças, considerando que a professora deixa de ser sensível aos momentos em que a criança entra em uma zona de desenvolvimento proximal ao tentar realizar uma experiência de aprendizagem e, não o conseguindo, vai necessitar do seu auxílio para aprender e passar ao próximo desenvolvimento.

De acordo com Rossetti-Ferreira, Mello, Vitoria, Gosuen e Chaguri (2001), o primeiro vínculo que se estabelece com uma criança é o emocional, e, no ambiente escolar da Educação Infantil, a relação afetiva é estabelecida principalmente com a professora, que pode dar apoio à criança, o que coloca ênfase na necessidade de a mesma desenvolver sua sensibilidade em relação às necessidades dessas crianças.

Outra interpretação para os dados de observação dessa professora é a de que também as políticas educacionais internas à instituição, permitindo a ocorrência de certas práticas tradicionais, igualmente se refletem no empenho da professora, como foi observado na situação filmada dos preparativos para a comemoração do "Dia das Mães", realizados em horário destinado ao trabalho com as crianças, desviando todo o empenho da professora, mobilizada somente para essa tarefa.

Levantar questões sobre políticas educacionais como essas pode ser um aspecto importante para momentos de formação contínua do professor, que nem sempre tem consciência do quanto ele está sujeito a essas circunstâncias quando exerce a sua prática docente. Essa tomada de consciência seria um momento crucial de desenvolvimento humano, em que o professor poderia realmente decidir-se a alterar a sua prática docente, conforme mostram Gonçalves e Maimone (2008), atendendo a um dos princípios da teoria vigotskiana, emprestado das categorias da teoria materialista histórico e dialética.

Dessa forma, estudos de observação em instituições educacionais mostram a necessidade de um diagnóstico da sala de aula antes que sejam implantados programas de formação de professores, porque podem fornecer pistas simples, mas importantes, de como auxiliar uma professora a melhorar a qualidade do ensino fornecido às crianças pequenas. Uma delas seria tornar lúdicas as atividades preparatórias para a alfabetização, já que isso tem mesmo de acontecer no último ano da Educação Infantil, embora a crença de pais, percebida pelas professoras, de que ao brincar a criança não está aprendendo muitas vezes possa desestimular tal iniciativa (Scriptori, Maimoni, Guimarães, Costa, \& Dias, 2006). Outra possibilidade seria desenvolver a preparação de datas comemorativas em conjunto com as crianças e pais, de forma coletiva (Maimone \& Santos, 2007). Seria uma oportunidade para demonstrar aos pais que "a criança começa a aprender de brincadeira", conforme defende Leontiev (1988, p. 64).

Uma vez feito o diagnóstico da prática, as vídeogravações seriam um recurso pedagógico também nos momentos de formação, quando a professora poder-se-ia observar em atuação e autorizar que colegas de trabalho pudessem assistir também aos vídeos e auxiliá-la nas suas dificuldades e/ou ressaltar boas situações de mediação, a exemplo do que fizeram Maimone e cols. (2007).

Outro aspecto a ser considerado na formação de uma professora com esse estilo mediacional refere-se à necessidade de serem criadas estratégias que possam ser utilizadas com o objetivo de desenvolver a autonomia de crianças dessa faixa etária e que vão logo ingressar no Ensino Fundamental. Filmagens de atuação em sala de aula mostrando situações reais, em que professores dão autonomia à criança pequena, podem ser de grande auxílio. Seria uma forma de contribuir para que não houvesse uma ruptura entre as duas etapas da Educação Escolar Básica: a Educação Infantil e o Ensino Fundamental, tendo como consequência o desajustamento da criança na sua nova etapa escolar em classe mais numerosa. Seria uma das características da aprendizagem na transição de um modelo dentro do binômio cuidar-educar da Educação Infantil para o modelo escolar.

Os dados da presente pesquisa nos permitem sugerir que estudos futuros sobre a atividade de ensino do professor da Educação Infantil devam ser realizados a partir de sua prática em sala de aula, de uma forma colaborativa, ou seja, com a participação efetiva do docente, que não pode ser tratado como um mero objeto de observação. Acreditamos que, assim, torna-se possível uma real mudança em sua prática social escolar pela adesão feita à proposta de formação. Além disso, fica evidente por esta pesquisa a possibilidade de um diagnóstico dessa prática antecedendo qualquer programa de formação, cuja avaliação dos resultados se dá pelos indicadores de mudança da prática docente, que é o critério de verdade dentro da metodologia proposta.

\section{Referências}

Campos, M. M. (1994). Educar e cuidar: questões sobre o perfil do profissional de educação infantil. Em Brasil. Ministério da Educação e do Desporto, Por uma política de formação profissional em educação infantil. Brasília: Mec.

Formosinho, J. O., \& Formosinho, J. (Orgs). (2001). Associação Criança: um contexto de formação em contexto. Braga, Portugal: Livraria Minho. 
Gasparin, J. L. (2005). Uma didática para a pedagogia históricocrítica. Campinas, SP: Autores Associados.

Gonçalves, G. S. de Q., \& Maimone, E. H. (2008). Formam-se professores avaliadores? Em A. R. Donatoni (Org.), Avaliação escolar e formação de professores. Campinas, SP: Alínea.

Klein, P. (1992). More intelligent and sensitive child (MISC): a new look at an old question. International Journal of Cognitive Education and Mediated Learning, 2(2), 105-15.

Kramer, S. (2001). A política da pré-escola no Brasil: a arte do disfarce. São Paulo: Cortez.

Leontiev, A. N. (1988). Uma contribuição à teoria do desenvolvimento da psique infantil. Em L. S. Vigotski, A. R. Luria, A. N. Leontiev, Linguagem, Desenvolvimento e Aprendizagem (M. da P. Vilalobos, Trad.). São Paulo: Ícone.

Maimone, E. H., \& Santos, K. T.dos. (2007). Relação família-creche: uma pesquisa autoscópica colaborativa. Anais. $4^{\circ}$. Encontro de Pesquisas em Educação. Uberaba.

Maimone, E.,H.; Oliveira, M. O. B. De, Vieira, G. M. S., \& De Pieri, M. G. C. (2007). Família-escola: uma relação possível. Nuances: Estudos sobre Educação, 14(15), 153-168.

Maimone, E. H., \& Gonçalves, G. S. de Q. (2010). A convergência da psicologia histórico-cultural e da pedagogia histórico-crítica em uma proposta de formação continuada de professores. Ensino em Re-vista, 17(1), 135-153.

Maimone, E. H., \& Tomás, D. N. (2005). Observação do educador infantil pela escala de empenho do adulto. Psicologia escolar e educacional, (9)2, 269-278.

Maimoni, E. H., \& Bortone, M. E. (2003). Colaboração família-escola: estudos sobre contribuição de pais em processos de aquisição de leitura e escrita. Em V. R. D. Gomes \& S. F. de O. Oliveira (Orgs.), A escola e a família: abordagens psicopedagógicas. Taubaté, SP: Cabral.

Mazzeu, F. J. C. (1998). Uma proposta metodológica para a formação continuada de professores na perspectiva histórico-cultural. Caderno Cedes, 44, 59-72.

Newman, F., \& Holzman, L. (2002). Lev Vygotsky: cientista revolucionário. (M. Bagno, Trad.). São Paulo: Loyola. (Trabalho original publicado em 1993)
Oliveira, Z. M., Mello, A. M., Vitoria, T., \& Rossetti-Ferreira, M. C. (1992). Creches: crianças, faz de conta \& cia. Petrópolis, RJ: Vozes.

Pascal, C., \& Bertram, T. (1996). Desenvolvendo a qualidade em parcerias: nove estudos de casos. Lisboa, Portugal: Porto Editora.

Ramos, R. M. (2007) Produção do conhecimento sobre formação de professores da Educação Infantil: dissertações e teses no período de 2000 a 2005. Dissertação de Mestrado, Instituto de Formação de Educadores, Universidade de Uberaba, Uberaba, Minas Gerais.

Rossetti-Ferreira, M. C., Mello, A. M., Vitoria, T., Gosuen, A., \& Chaguri, A. C. (Orgs). (2001). Os fazeres na educação infantil (3a ed.). São Paulo: Cortez.

Sadalla, A. M. F. De, \& Larocca, P. (2004). Autoscopia: um procedimento de pesquisa e de formação. Educação e Pesquisa, 30(3), 419-433.

Scriptori, C. C., Maimone, E. H., Guimarães, F. O., Costa, V., \& Dias, E. (2006). Conhecendo as concepções de professoras de Educação Infantil. Revista da Sociedade de Psicologia do Triângulo Mineiro, 10(1), 53-61.

Silva, C. E. (2004). Formação continuada de educadoras infantis: uma proposta de intervenção. Dissertação de Mestrado, Faculdade de Educação, Universidade Federal de Uberlândia, Minas Gerais.

Tomás, D. N. (2010) Conhecendo o perfil mediacional de mães sociais: um estudo sobre as interações em abrigos. Dissertação de Mestrado, Instituto de Psicologia, Universidade Federal de Uberlândia, Minas Gerais.

Vectore, C., \& Kishimoto, T. M. (2001). Por trás do imaginário infantil: explorando a brinquedoteca. Psicologia Escolar e Educacional, $5(2), 59-65$.

Vigotski, L. S. (1987). Pensamento e linguagem (J. L. Camargo, Trad.). São Paulo: Martins Fontes. (Trabalho publicado em 1961)

Vigotskii, L. S., Luria, A. R., \& Leontiev, A. N. (1988). Linguagem, desenvolvimento e aprendizagem (M. da P. Vilalobos, Trad.). São Paulo: Ícone.

Vigotski, L. S. (2003). O desenvolvimento psicológico na infância. (C. Berliner, Trad.) São Paulo: Martins Fontes. (Trabalho original publicado em 1982) 


\section{Sobre as autoras}

Helena de Ornellas Sivieri Pereira (helena.sivieri@gmail.com)

Universidade Federal do Triângulo Mineiro, Doutora em Psicologia pela FFCLRP/USP

Endereço: Av. Isabel Bazaga, 43; 38082-156 - Manoel Mendes - Uberaba/MG

Eulália Henriques Maimone (eulaliamaimone@netsite.com.br)

Docente aposentada da Universidade Federal de Uberlândia, Doutora em Psicologia pela USP-SP

Endereço: Av. Dr. Misael Rodrigues de Castro, 569 - Santa Mônica. CEP 38.408-184 - Uberlândia - MG

Aline Patrícia Oliveira (aline.psic@hotmail.com)

Aluna bolsista CNPq

Endereço: Av. Dr. Hélio Luiz da Costa, 544 - Conjunto Frei Eugênio. CEP 38081-100 - Uberaba - MG

Este trabalho é oriundo de Programa de Iniciação Científica desenvolvido através do PIBIC/ UNIUBE, em 2008, com apoio financeiro do CNPq. 